\title{
A Review of Literature of Initial Trust in E- Services: The Case of Internet Banking Services in Jordanian Context
}

\author{
Ali O. Al-Jaafreh ${ }^{1}$, Raid Al-adaileh ${ }^{2}$, Asif Gill ${ }^{3}$, Ahmed Al-Ani ${ }^{4}$ and Yehia alzoubi ${ }^{5}$ \\ 1,3,4,5 University of Technology, Sydney, Australia \\ ${ }^{2}$ Mutah University, Al-Karak, Jordan
}

Correspondence should be addressed to: Ali O. Al-Jaafreh; Ali.O.Aljaafreh@student.uts.edu.au

Received date: 9 September 2013; Accepted date: 30 January 2014; Published date: 21 October 2014

Academic Editor: Mohd Khairudin Kasiran

Copyright (C) 2014. Ali O. Al-Jaafreh, Raid Al-adaileh, Asif Gill, Ahmed Al-Ani and Yehia alzoubi. Distributed under Creative Commons CC-BY 3.0

\begin{abstract}
Trust in prior marketing research is considered to be the milestone in the dealing between two entities. Likewise, information systems' researchers considered customer's trust in eServices to be an essential element in accepting such services. In the case of internet banking services (IBS) in the Jordanian context, the early stage of trust will be under investigation since the majority of people are not adopters for IBS. The main aim of this paper is to identify, define, and categorise the factors that influence Jordanian's initial trust in IBS. A systematic qualitative literature survey approach has been adopted and reports the following categories: firstly, trust bases category includes: personality-based trust, cognition-based trust (Reputation), institutional-based trust (structural assurance); secondly, Information Technology category includes website factors (security, privacy, and general online experiences); thirdly, social factors (national culture); finally, diffusion of innovation factors: Relative advantages and compatibility. The selection of the previous factors depends on the user characteristics (no prior experience in IBS), and context characteristics (national culture of the Jordanian context). These factors can be useful for increasing organisations' (i.e. banks) understanding and addressing customer's initial trust in IBS in the Jordanian context.
\end{abstract}

Keywords: Initial trust, internet banking services, intention to use, Jordanian Context

\section{Introduction}

Early 1980s, Banks attempted to provide their customers with remote banking services which represented the foundation of internet banking services (Bidgoli 2004).
Dandapani \& Curran (2004) argued that internet banking services (IBS) have become a necessity in our daily life. In this study, we define IBS as the customer's ability to access their bank accounts and complete all their banking transactions 
through bank websites without a need for a physical presence at banks. In Jordan, the year 2000 was the starting point of IBS (Awamleh et al. 2003). Now, in 2013, banks that offer IBS in Jordan are 20. (Detailed list of Jordanian banks can be provided on request).

According to annual governmental reports in Jordan (Ministry of Information and Communications Technology 2011; Telecommunications Regulatory Commission 2011, 2012), 55.9\% of Jordanians had internet connection at that time. Due to this diffusion of the internet in Jordan, the adoption and usage of e-services would grow considerably. Nevertheless, the usage of e-services in general and IBS in particular was extremely low; the latest governmental report in Jordan showed that only $3.6 \%$ of Jordanians use IBS (Department of Statistics 2009). (No further latest report).

Previous studies which were conducted in Jordan found many factors affect the adoption of new technologies. Most of these studies have extended previous theories by adding other factors such as culture, trust, technological factors, and other social factors. For instance, the technology acceptance model (TAM) was used in Al Sukkar and Hasan 2005, others combined the diffusion of innovation (DOI) theory and TAM (e.g. Alomari 2012), or adopted the unified theory of acceptance and use of techonolgy (UTAUT) (e.g. AbuShanab and Pearson 2009). We noticed that most of the previous studies in Jordan shared the investigation of trust and pointed that trust plays a significant role in adopting new technologies (e.g. Abbad 2011). This study presents a move through investigation that aims at identifying factors that affect trust.

According to McKnight et al. (1998) trust is a crucial element for dealing in an off-line environment, and a number of more recent studies consider trust to be a determinant factor in online dealing (Kim et al. 2009; Lin et al. 2011; McKnight et al. 2002b; Susanto et al. 2013; Zhou 2011). Accordingly, trust plays a significant role in encouraging customers to use IBS. Since initial trust is the first step of trust, this study focuses on this important part of trust and the factors that affect it.

Initial trust in developed countries is expected to be different from developing countries. Furthermore, most of the initial trust literature was conducted in developed countries (Susanto et al. 2013). Moreover, most of the literature was conducted in developed countries (USA: 10, China: 4, UK: 2, Australia: 1, Korea: 1, and Taiwan: 1). On the other hand, we found only 4 studies that were conducted in developing countries (Malaysia: 2, Indonesia: 1, and Saudi Arabia: $1)$. Therefore, lack in the number of studies in developing countries shows the necessity to do further research in this area. Consequently, the research question of this study is: what are the factors influencing the customer's initial trust of IBS in the Jordanian context? To answer this question, we aim to provide an extensive critical review of the available studies concerning the factors that influence the customer's initial trust. Consequently, we can do future research on the customer's initial trust of IBS in the Jordanian context.

The rest of this paper is structured as following: in the next section, a research method is presented to discuss the path and steps of our research. Then, a section for theoretical background of IBS and trust is presented. In addition, researchers categorise the factors which are mentioned in the existent literature of initial trust.

\section{Research Method}

In this study, we analyse the current situation of internet banking services' (IBS) usage in the Jordanian context. And, we focus on trust as one of the barriers of using IBS in Jordan. A qualitative analysis for the literature has been done in order to define the factors that influence trust of IBS. This research adopts the design science research process (DSRP) model which was proposed by Peffers et al. (2006). Figure 1 shows the sequence of six research steps. This paper represents the first two steps: (problem identification and motivations and research objectives, questions, and literature). 


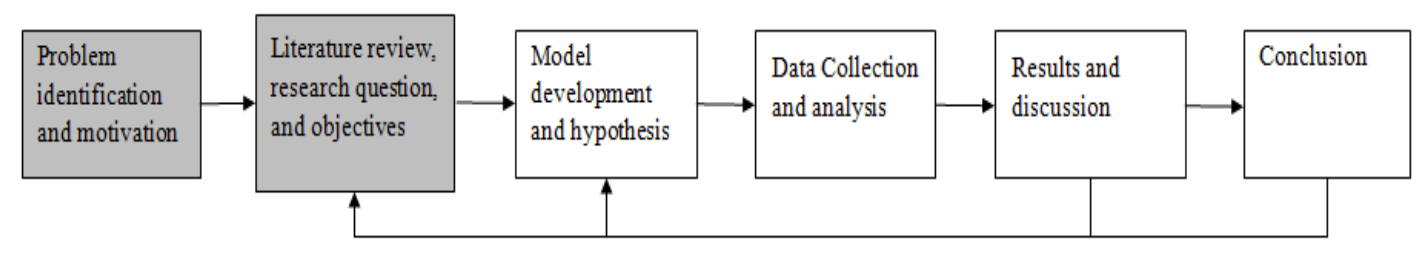

Figure 1: Research and Analysis process

The empirical research method goes with six steps. As shown in figure 1, the research starts by identifying a problem and motivations to solve it. In the second step, the researcher develops the objectives of the study and starts collecting data about the problem from different resources. For the literature part, the researchers use some keywords (e.g. initial trust, culture, Arab countries, and developing countries) to conduct their research in databases such as Springer, Emerald, Google scholar, and EBSCO. The researchers analysed classified the articles they got from those databases. Then, they considered the articles which investigated initial trust. In future research, the researchers are going to propose a model to examine the relationships between the selected variables themselves, and with initial trust.

\section{Theoretical Background}

\section{Internet Banking Services in Jordan}

Internet Banking service (IBS) in Jordan started in 2000. Awamleh et al. (2003) stated that two banks in Jordan (Arab Bank and Jordan Kuwait Bank) have already some services delivered on their websites since 2000. In 2013, we have checked the websites of the Jordanian banks to check the availability of IBS and found that there are out of 16 Jordanian commercial banks three of them don't offer IBS, and out of 9 foreign banks two of them don't offer IBS. In total, the number of Jordanian banks that offer IBS is 20 out of 25. (A detailed list of Jordanian banks can be provided on request).
Recent Jordanian studies in the field of management information systems considered the lack of user's trust to be a barrier which affects information system success (Abbad 2011; AbuShanab and Pearson 2009; AL-Majali and Mat 2011; Al Sukkar and Hasan 2005). In addition, AlHujran et al. (2011) reported that trust is a major barrier in e-Government adoption. Due to the importance of trust, we focus on the early stage of the customer's trust (initial trust) of IBS in the Jordanian context.

\section{Initial Trust}

The concept of trust is widely used in many sciences. Basically, trust is divided into initial trust and ongoing trust. The need for previous knowledge and a period of time are the main differences that distinguish the formation process of the two types of trust. Initial trust is formed temporary and does not rely on any previous knowledge (Kim \& Tadisina 2007). On the contrast, ongoing trust needs long time to be formed and it is based on knowledge or previous experience, which is gained after the initial trust formation.

In this study, the researchers focus on customer's initial trust and the factors that influence it. That is because a sample of this study will be the Jordanians who have never used IBS. For the purpose of this study, initial trust can be defined as the level of trust that the trustor (i.e. customer) has about unfamiliar trustee (i.e. IBS) without relying on previous knowledge or experience of using it. 


\section{Literature Review}

This section discusses the literature review of initial trust and clarifies the factors that affect it. After we had reviewed 21 studies, we built Table 1 which categorises the literature's factors. The first author labels four categories which are: trust bases category, Information Technology category, social category, and diffusion of innovation theory category. Eight sub-categories and 26 dimensions are found. This draws our attention to the need of human and Information technology alignment. The labelling of categories identified from the literature is subject to human error and mistakes, which may lead to inconsistency (Weber 1990). Therefore, two researchers independently and concurrently checked the categories and their inter-connections; which were then adjusted by the first author of this paper. This has been done to minimise any possible omissions or errors.

\section{Trust bases factors}

Trust bases include Personality-based, cognition-based, institution-based, calculative-based, and knowledge-based. The name of this category comes from the source, nature, and the effect of these factors on the customers' perception. The following paragraphs discuss these subcategories briefly.

- Personality-Based Trust: personalitybased trust is defined as propensity or tendency to believe in the positive attributes of others in general (McKnight et al. 2002b). It is also known as propensity to trust or disposition to trust. Some studies claimed that faith in humanity and trusting stance are the two dimensions which represent personality-based trust (see table1, row 1). However, most of the literature indicates that personality-based trust has been widely examined as one construct (without any dimensions) (see row 3)

- Cognition-Based Trust: It represents the way that trust is formed during the first impression or meeting rather than first-hand knowledge or previous interaction (Meyerson et al. 1996). Table 1 explains that cognition-based includes four dimensions which are: reputation, size, corporate image, and willingness to customise.

- Institutional-Based Trust: Two institutional predictors of initial trust have been introduced; situational normality (SN) and structural assurance (SA). According to Baier (1986) and Lewis and Weigert (1985), SN means that the normality of such a situation makes someone believe that his/her order is in a proper environment and will succeed. SA means that the existence of structures such as guarantees, regulations, rules, polices, security, legal resources, or other procedures will increase and promote success (Shapiro 1987; McKnight 1998).

- Calculative-based trust: Gefen et al. (2003) illustrated that trust in this view results from analysing the ongoing relationships; it is shaped through rational assessments of the costs and benefits of another party in the relationship. This sub-category does not have dimensions (see row 8).

- Knowledge-based trust (a.k.a. Familiarity): results from the accumulated experience of dealing with the other parties (Gefen et al. 2003). In our case, it means the experience of using IBS itself.

\section{Information Technology factors}

This category is defined as any factor related to information technology itself. Two main sub-categories represent the technological part, website factors and institutional-based (technological part). These sub-categories and their dimensions are discussed below.

- Website factors: includes all the factors related to a website. Ten factors were found in the literature. Most of the literature focused on security and privacy which were identified as major customer's concern in online trust. Others examined factors from 
existed models and theories (perceived usefulness and perceived ease of use, enjoyment of technology, compatibility). In addition, website quality, information quality, and website usability were taken into account. Finally, the familiarity with online environment (user's previous experiences) was considered.

- Technological institutional-based: contains two dimensions which are technological situational normality (refers to the experience which the user has from dealing with such situation), and technological structural assurance (refers to the existence of technological safeguards (e.g. encryption)), certifications of a thirdparty, and feedback mechanisms.

\section{Social category}

Culture factors: is defined as all factors related to social life and dealing directly with people. There are two dimensions that represent this sub-category, which are: interaction (means the availability of inter- consumer communication), word of mouth (means the recommendation to use or not use coming either from tie strength or relational content). Both of these dimensions have the same meaning but in a different way. The characteristic of word of mouth existed in collectivism societies such as the Jordanian society.

Governmental support (support that the government gives to adopt IBS)

\section{Diffusion of innovation theory category}

Two dimensions were found in the literature, which are: relative advantages/benefits (means the benefits realized when a new service offers more value to customers than existing ones), and compatibility (means The degree to which an innovation is perceived as consistent with the existing values, past experiences, and needs of potential adopters). 


\begin{tabular}{|c|c|c|c|}
\hline Category & Sub-Category & dimensions & Source \\
\hline \multirow{11}{*}{$\begin{array}{l}\text { Trust bases } \\
\text { factors }\end{array}$} & \multirow[t]{3}{*}{ Personality-based } & Faith in humanity & \multirow{2}{*}{ Li et al. (2008), McKnight et al. (2002b), Gefen (2000) , Alsaghier (2010) } \\
\hline & & Trusting stance. & \\
\hline & & $\begin{array}{l}\text { No dimensions (this means that the } \\
\text { researchers examined it as one } \\
\text { construct) }\end{array}$ & $\begin{array}{l}\text { Kim and Prabhakar (2004), Susanto et al. (2013), Wu et al. (2010), Azam et al. (2012), Kim } \\
\text { et al. (2009), Lin et al. (2011), Zhou (2011), Zhou and Tian (2010), Gefen and Straub } \\
\text { (2004), Koufaris and Hampton-Sosa(2004), Chen \& Barnes (2007) }\end{array}$ \\
\hline & \multirow{4}{*}{ Cognition-based } & Reputation. & $\begin{array}{l}\text { Li et al (2008), Eastlick and Lotz (2010), Susanto et al. (2013), McKnight et al. (2002a), } \\
\text { Kim et al. (2009), L in et al. (2011). }\end{array}$ \\
\hline & & Corporate Image & Zhou and Tian (2010) \\
\hline & & Size. & Jarvenpaa et al (2000), Koufaris and Hampton-Sosa(2004), Chen \& Barnes (2007), \\
\hline & & Willingness to customise & Chen \& Barnes (2007), Koufaris and Hampton-Sosa(2004) \\
\hline & \multirow[b]{2}{*}{ Institutional-based } & Situational normality & $\begin{array}{l}\text { Yousafzai et al. (2005), McKnight et al. (2002b), Li et al (2006), Gefen et al. (2003), } \\
\text { Alsaghier (2010), Li et al (2008) }\end{array}$ \\
\hline & & Structural assurance & $\begin{array}{l}\text { Kim and Prabhakar (2004), Yousafzai et al. (2005), McKnight et al. (2002b), Li et al. (2006), } \\
\text { Kim et al. (2009), Lin et al. (2011), Zhou (2011), Gefen et al. (2003), Alsaghier (2010), Li et } \\
\text { al. (2008) }\end{array}$ \\
\hline & Calculative-based & No dimensions & Li et al. (2008), Gefen et al. (2003). \\
\hline & Knowledge- based & No dimensions & Gefen et al. (2003), Gefen and Straub (2004), \\
\hline \multirow{10}{*}{$\begin{array}{l}\text { Information } \\
\text { Technology } \\
\text { factors }\end{array}$} & \multirow{9}{*}{ Website factors } & Security & $\begin{array}{l}\text { Susanto et al. (2013), Yousafzai et al. (2009), Azam et al. (2012), Koufaris and Hampton- } \\
\text { Sosa(2004), (Chen \& Barnes 2007), Lean et al. (2009, Li et al. (2008), McKnight et al. } \\
(2002 a)\end{array}$ \\
\hline & & privacy & $\begin{array}{l}\text { Eastlick and Lotz (2010), Susanto et al. (2013), Yousafzai et al. (2009), Azam et al. (2012), } \\
\text { Lean et al. (2009), Li et al. (2008), McKnight et al. (2002a) }\end{array}$ \\
\hline & & Website usability. & Susanto et al. (2013), \\
\hline & & Perceived information quality. & Lin et al. (2011) \\
\hline & & Perceived Web Site Quality. & Zhou and Tian (2010), McKnight et al. (2002a), Yousafzai et al. (2005). \\
\hline & & Perceived usefulness & Chen \& Barnes (2007), Koufaris and Hampton-Sosa(2004), Alsaghier (2010) \\
\hline & & Perceived ease-of-use & Chen \& Barnes (2007), Koufaris and Hampton-Sosa(2004), Alsaghier (2010) \\
\hline & & Enjoyment of technology & Chen \& Barnes (2007) \\
\hline & & Familiarity with online environment & Alsaghier (2010), Eastlick and Lotz (2010), Li et al. (2008). \\
\hline & Technological & Technical Situational normality & Li et al. (2008), Eastlick and Lotz (2010), \\
\hline
\end{tabular}




\begin{tabular}{|l|l|l|l|}
\hline & Institutional-based & Technical Structural assurance & Li et al. (2008), McKnight et al. (2002a). \\
\hline Social factors & \multirow{2}{*}{ culture and others } & Word Of Mouth & Kim and Prabhakar (2004) \\
\cline { 3 - 4 } & & interaction & Chen \& Barnes (2007) \\
\cline { 3 - 4 } & Government support. & Susanto et al. (2013) \\
\hline $\begin{array}{l}\text { Diffusion of } \\
\text { innovation } \\
\text { factors }\end{array}$ & No sub-category. & Relative benefits/advantages & Kim et al. (2009), Susanto et al. (2013) \\
\cline { 3 - 4 } & & Compatibility & Lin et al. (2011) \\
\hline
\end{tabular}




\section{Discussion}

This paper has explained the current situation of internet banking services' (IBS) usage in Jordan. Through survey related literature, we have found that most recent studies named trust as one of the most important impediment of using, accepting, or adopting IBS. Thus, we have focused on the factors which influence trust of using IBS among Jordanians. Since more than 96 $\%$ of Jordanians have not used IBS before (no previous experiences in IBS), this study has focused on customer's initial trust which suit the characteristics of the study population. Obviously, the intensive literature survey that we have made therefore gives us a broad view of customer's initial trust and the factors that influence it.

Based on the literature review, there are many dimensions that do not suit the particular problem of IBS adoption in the Jordanian context, since these dimensions assume that users (i.e. customers) should have previous experiences and knowledge with the trustee (e.g. Calculative-based, knowledge-based). In addition, many dimensions have similarity in their meaning (e.g. website usability and perceived usefulness and relative advantages). Moreover, some dimensions are more comprehensive than others (e.g. website quality is more comprehensive than information quality). Finally, the social factors which were mentioned in our literature (i.e. word of mouth and interaction) represent a part of the Jordanian culture. Consequently, recent studies in Jordan showed that the Jordanian culture has a significant impact on adopting new technologies (e.g. Al-Hujran 2008). Thus, national culture should be considered in our research. In summary, our dimensions from trust bases category are: personality-based trust, cognition-based trust (Reputation), and Institutional-based trust; from the social factors (national culture); from the diffusion of innovation theory factors: relative advantages and compatibility; from technological category: website factors (security, privacy, general online experiences).

\section{Conclusion}

The aim of the paper is to identify factors influencing the customer's initial trust of internet banking services (IBS) in the Jordanian context. Analysis of existing studies enabled us to identify the most important and suitable factors of the problem under consideration i.e. the adoption of IBS in the Jordanian society. In this study, we focus mainly on the factors that may affect the customer's initial trust without any need for any previous experiences. Our analysis of the literature review has showed the most important and suitable factors for our study. The context of this study is (i.e. Jordanian context), by necessity, leading us to select the factors based on its characteristics. In other words, we took into account the lake of Jordanians' experiences in using IBS and the national culture. Depending on these two criteria, we select the factors that suit our study. We have broadly divided these factors into four categories. Relationships between these factors and initial trust will be validated in the context of IBS adoption in Jordan, and will be the focus of our future work.

\section{References}

1. Abbad, M. 2011. E-banking in Jordan. Behavior \& Information Technology, 1-14.

2. Abushanab, E. \& Pearson, J. 2009. Internet banking in Jordan: An arabic instrument validation process. The International Arab Journal of Information Technology, 6, 235-246.

3. AL Sukker, A. \& Hasan, H. 2005. Toward a model for the acceptance of internet banking in developing countries. Information Technology for Development, 11, 381-398.

4. Alhujran, 0. \& Chatfield, A. Toward a Model for e-Government Services Adoption: The Case of Jordan. Proceedings of the 8th European Conference on eGovernment, 2008. Ecole Polytechnique, 13-22.

5. AL-Hujran, 0., AL-Dalahmeh, M. \& Aloudat, A. 2011. The Role of National Culture on Citizen Adoption of Egovernment Services: An Empirical Study. 
Electronic Journal of E-Government, 9, 93106.

6. AL-Majali, M. \& Mat, N. 2011. Modeling the antecedents of internet banking service adoption (IBSA) in Jordan: A structural equation modeling (SEM) approach. Journal of Internet Banking and Commerce, 16.

7. Alomari, M., Woods, P. \& Sandhu, K. 2012. Predictors for e-government adoption in Jordan: Deployment of an empirical evaluation based on a citizencentric approach. Information Technology \& People, 25, 207-234.

8. Alsaghier, H. 2010. An Investigation of Critical Factors Affecting Citizen Trust in EGovernment: Empirical Evidence from Saudi Arabia. PhD PhD, Griffith University.

9. Awamleh, R., Evans, J. and Mahate, A. 2003. Internet Banking in Emergency Markets: The Case of Jordan - a note. 8. Available:

http://www.arraydev.com/commerce/JIB C/0306-03.htm [Accessed 20 September 2012].

10. Azam, A., Qiang, F. \& Abdullah, M. I. Consumers' E-commerce Acceptance Model: Antecedents of Trust and Satisfaction Constructs. Business Engineering and Industrial Applications Colloquium (BEIAC), 2012 IEEE, 2012. IEEE, 371-376.

11. Baier, A. 1986. Trust and Antitrust. Ethics, 96, 231-260.

12. Bidgoli, H. 2004. The internet encyclopedia, New York, John Wiley and Sons.

13. Chen, Y.-H. \& Barnes, S. 2007. Initial Trust and Online Buyer Behaviour. Industrial Management \& Data Systems, 107, 21-36.

14. Dandapani, S. \& Curran, D. 2004. Separation Friendly Mitsunobu Reactions: A Microcosm of Recent Developments in Separation Strategies. Chemistry-A European Journal, 10, 3130-3138.

15. Department of Statistics. 2009. "Survey the Use of Information Technology within Homes 2009 Analytical Report," DOS, Jordan, p. 71.
16. Eastlick, M. \& Lotz, S. 2011. Cognitive and Institutional Predictors of Initial Trust Toward an Online Retailer. International Journal of Retail \& Distribution Management, 39, 234-255.

17. Gefen, D. \& Heart, T. 2006. On the Need to Include National Culture as a Central Issue in E-commerce Trust Beliefs. Journal of Global Information Management (JGIM), 14, 1-30.

18. Gefen, D. \& Straub, D. 2004. Consumer Trust in B2C E-commerce and The Importance of Social Presence: Experiments in E-products and E-services. Omega, 32, 407-424.

19. Gefen, D. 2000. E-commerce: The Role of Familiarity and Trust. Omega, 28, 725737.

20. Gefen, D., Karahanna, E. \& Straub, D. 2003. Trust and TAM in Online Shopping: an Integrated Model. MIS quarterly, 51-90.

21. Jarvenpaa, Tractinsky \& Vitale, M. 2000. Consumer Trust in an Internet Store. Information Technology and Management, 1, 45-71.

22. Kim, E. \& Tadisina, S. 2007. A model of customers' trust in e-businesses: microlevel inter-party trust formation. Journal of Computer Information Systems, 48, 88104.

23. Kim, G., Shin, B. \& Lee, H. 2009. Understanding Dynamics Between Initial Trust and Usage Intentions of Mobile Banking. Information Systems Journal, 19, 283-311.

24. Kim, K. \& Prabhakar, B. 2004. Initial Trust and the Adoption of B2C ECommerce: The Case of Internet Banking. ACM sigmis database, 35, 50-64.

25. Koufaris, M. \& Hampton-Sosa, W. 2004. The Development of Initial Trust in an Online Company by New Customers. Information \& Management, 41, 377-397.

26. Lwis, J. \& Weigert, A. 1985 . Trust as a Social Reality. Social forces, 63, 967-985.

27. Li, X., Hess, T. \& Valacich, J. 2006. Using Attitude and Social Influence to Develop an Extended Trust Model for Information Systems. ACM sigmis database, 37, 108124. 
28. Li, X., Hess, T. \& Valacich, J. 2008. Why Do We Trust New Technology? A Study of Initial Trust Formation with Organizational Information Systems. The Journal of Strategic Information Systems, 17, 39-71.

29. Lin, J., Lu, Y., Wang, B. \& Wu, S. 2011. Initial Trust and Adoption of Mobile Brokerage Service. International Journal of Mobile Communications, 9, 124-143.

30. Mcknight, D. H., Cummings, L. \& Chervany, N. 1998. Initial Trust Formation in New Organizational Relationships. Academy of Management review, 473-490.

31. Mcknight, H., Choudhury, V. \& Kacmar, C. 2002a. Developing and Validating Trust Measures for E-Commerce: An Integrative Typology. Information systems research, 13, 334-359.

32. Mcknight, H., Choudhury, V. \& Kacmar, C. 2002b. The Impact of Initial Consumer Trust on Intentions to Transact with a Web Site: a Trust Building Model. The Journal of Strategic Information Systems, 11, 297323.

33. Meyerson, D., Weick, K. \& Kramer, R. 1996. Swift Trust and Temporary Groups. Trust in Organizations: Frontiers of Theory and Research, 166, 195.

34. Ministry of Information and Communications Technology. 2011. "Annual Report for Performance and Acheivements," MoICT, Jordan, p. 29.

35. Peffers, K., Tuunanen, T., Gengler, C., Rossi, M., Hui, W., Virtanen, V. \& Bragge, J. The Design Science Research Process: a Model for Producing and Presenting Information Systems Research. Proceedings of the first international conference on design science research in information systems and technology (DESRIST 2006), 2006. 83-106.

36. Shapiro, S. 1987. The social control of impersonal trust. American journal of Sociology, 623-658.

37. Susanto, A., Lee, H., Zo, H. \& Ciganek, A., 2013. User Acceptance of Internet Banking in Indonesia: Initial Trust Formation. Information Development, 1-14.
38. Telecommunications Regulatory Commission. 2011. "Annual Report 2011," TRC, Jordan, p. 54.

39. Telecommunications Regulatory Commission. 2012. "Quarterly Indicator." Retrieved 19 September 2012, from http://www.trc.gov.jo/index.php?option=c om_content\&task=view\&id=1941\&Itemid= 508\&lang=english\&lang=english

40. Weber, E. \& Hsee, C. 1998. Crosscultural differences in risk perception, but cross-cultural similarities in attitudes towards perceived risk. Management Science, 44, 1205-1217.

41. Wu, G., Hu, X. \& Wu, Y. 2010. Effects of Perceived Interactivity, Perceived Web Assurance and Disposition to Trust on Initial Online Trust. Journal of Computer-Mediated Communication, 16, 126.

42. Yousefzai, S., Pallister, J. \& Foxall, G. 2005. Strategies for Building and Communicating Trust in Electronic Banking: A Field Experiment. Psychology \& Marketing, 22, 181-201.

43. Yousefzai, S., Pallister, J. \& Foxall, G.2009. Multi-Dimensional Role of Trust in Internet Banking Adoption. The Service Industries Journal, 29, 591-605.

44. Zhou, M. \& Tian, D. 2010. An Integrated Model of Influential Antecedents of Online Shopping Initial Trust: Empirical Evidence in a Low-Trust Environment. Journal of International Consumer Marketing, 22, 147-167.

45. Zhou, T. 2011. An Empirical Examination of Initial Trust in Mobile Banking. Internet Research, 21, 527-540. 